\title{
CHIKUNGUNYA: MOLECULAR ASPECTS, CliniCAL OUTCOMES AND PATHOGENESIS
}

\author{
Eduardo Bautista-Reyes ${ }^{1}$, Daniel Núñez-Avellaneda ${ }^{1}$, Luis Antonio Alonso-Palomares ${ }^{1}$ \\ AND MA ISABEL SALAZAR $1,2 *$
}

${ }^{1}$ Laboratory of Cellular Immunology and Immunopathogenesis, Department of Immunology, and ${ }^{2}$ Laboratory of Virology, Department of Microbiology. Escuela Nacional de Ciencias Biológicas, Instituto Politécnico Nacional, Mexico City, Mexico

\begin{abstract}
The alarming worldwide emergence of the chikungunya virus began in the last decade. Since the first autochthonous transmission in Mexico in November of 2014, the virus has spread throughout the country, resulted in multiple outbreaks. This virus produces an acute and self-limiting disease characterized by fever, polyarthralgia, myalgia, exanthema, and general malaise. It is transmitted to humans by the bite of Aedes aegypti and A. albopictus mosquitoes. The fact that the clinical presentation is similar to that produced by other arboviruses complicates its clinical diagnosis. The chronic stage of the disease can cause severe consequences lasting months or years, from local arthralgia to rheumatoid arthritis. In this review, we emphasize the public health threat posed by this highly disabling emerging disease, the clinical outcomes, and its possible physiopathological process. We outline the diagnosis and the impact that this virus has had in Mexico since its introduction.
\end{abstract}

Key words: Chikungunya. Pathogenesis. Molecular aspects.

\section{INTRODUCTION}

Chikungunya virus (CHIKV) is an emerging arbovirus in the Americas that affects humans, causing chikungunya fever. The virus was initially isolated from human serum and infected mosquitoes during an epidemic in Tanzania in 1953. In 2004, CHIKV reappeared on the coast of Kenya and spread to the Comoro islands, where 5,000 cases were reported ${ }^{1}$. In 2005-2006, the virus disseminated to other islands of the Indian Ocean, mainly La Réunion where it is estimated that 300,000 people out of a population of 785,000 were infected, leading to 237 deaths $^{2,3}$. The epidemic reached the Asian continent in 2006 when large outbreaks in India affected an estimated 1.5 million individuals ${ }^{4}$.

On December 6, 2013, the Pan American Health Organization (PAHO) confirmed the autochthonous transmission of CHIKV in the Americas, detecting cases of the infection in the island of San Martín ${ }^{5,6}$. The entry of the virus to this continent has led to its spread to different areas of the Americas, mainly countries in the

\section{Corresponding author:}

* Ma Isabel Salazar

Laboratorio Virología, Departamento Microbiología

Escuela Nacional de Ciencias Biológicas,

Instituto Politécnico Nacional

Prol. Carpio y Plan de Ayala, s/n

Col. Santo Tomás

C.P. 11340, Ciudad de México, México

E-mail: isalazarsan@yahoo.com

Received for publication: 25-08-2016

Approved for publication: 12-04-2017

doi: 10.24875/RIC.17002029 
Figure 1. Enzootic and epidemic cycles of chikungunya virus in nature. In the enzootic cycle, the virus maintains itself in nature in wild primates and is transmitted by Aedes furcifer and $A$. taylori mosquitoes. In this cycle in the wild, infections with human hosts occur sporadically, are local and in sylvatic environments. In the endemic cycle, the transmitting species are $A$. albopictus and $A$. aegypti. Infections occur in humans in semi-urban environments, with the mosquito-human-mosquito route leading to large epidemics. The mutation of A226V has favored the adaptation of the vector ${ }^{15}$.

\section{ENZOOTIC CYCLE Wild primates}



Epidemic cycle Humans

Peridomestic mosquitoes: Aedes albopictus Aedes aegypti

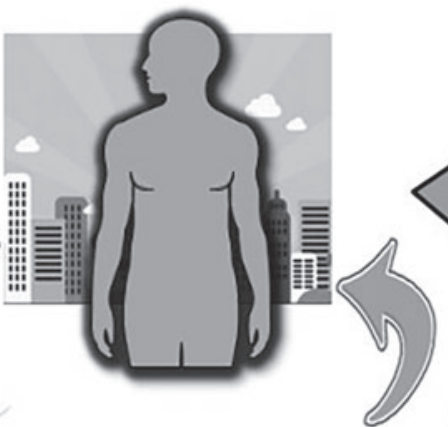
:

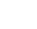

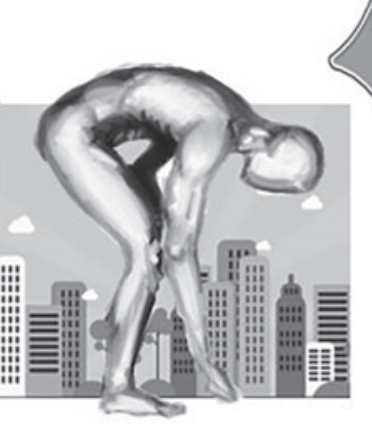

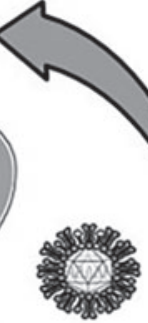

Mutation A226V in E1 protein central region ${ }^{7}$. The $\mathrm{A} 226 \mathrm{~V}$ mutation in the $\mathrm{E} 1$ protein of the virus appears to be directly responsible for the important increase in infectivity of CHIKV in Aedes albopictus mosquitoes, an event that led to the most efficient viral dissemination known in humans ${ }^{8}$ (Fig. 1).

In Mexico, in late 2014 during an outbreak of febrile illness in Chiapas, $79 \%$ of analyzed samples tested positive for $\mathrm{CHIKV}^{9}$ and $A$. aegypti was identified as its primary vector ${ }^{10}$. In 2015, 11,577 cases were confirmed, with four deaths, mostly in the south-central states of Mexico (DGE/InDRE, 2016; OPS/OMS, 2016). An extensive sequence analysis of autochthonous Mexican virus isolates showed that these belonged to the Asian genotype ${ }^{11}$. In Yucatan, Mexico, CHIKV from the Asian lineage was also isolated from febrile individuals, one case in coinfection with DENV-1 ${ }^{12}$. An extensive discussion on the pattern of transmission for CHIKV in the Americas and its association with poor control measures has been published ${ }^{13}$.

\section{GENERAL ASPECTS AND VIRUS REPLICATION}

The virus belongs to the Alphavirus genus in the Togaviridae family, and is made up of an icosahedral capsid and a membrane envelope. The size of the virion varies from 60 to $70 \mathrm{~nm}$. Its genome consists of a single-stranded, positive-sense RNA molecule of approximately $12 \mathrm{~Kb}$. The genome consists of two open reading frames (ORF) that codify for nine proteins: five structural proteins (SP), including the capsid (C), the membrane (6k), and three envelope proteins (E1, E2, E3); and four non-structural proteins (NSP), including NS1, NS2, NS3 and NS4 ${ }^{14}$. 
There are three genotypes of CHIKV, named after the geographic region in which they were first detected: the West African genotype, the Asian genotype, and the East/Central/South African genotype (ECSA). To date, no serotypes of CHIKV have been found, meaning that all genotypes are antigenically similar ${ }^{15,16}$.

The name of the virus and disease comes from the Bantu language of the Makonde people, meaning "that which bends up", referring to the curved posture of people with the disease, resulting from the painful arthralgia produced by an infection with $\mathrm{CHIKV}{ }^{17,18}$. CHIKV is capable of propagating in an ample variety of the infected cells of hosts, which include humans, monkeys, birds, cattle, and rodents. In humans, the surface glycoprotein E2 ${ }^{19}$ of the virion interacts with susceptible host cells that present receptors to this protein on their surface.

One of the proposed receptors for this virus is prohibitin-1 (PHB-1). However, not much is known about the participation of this protein in viral pathogenesis ${ }^{20}$. The PHB-1 is a protein of $32 \mathrm{kDa}$ involved in the regulation of proliferation and apoptosis, among other functions. This protein is normally located in the mitochondria and its expression is affected by high levels of interferon (IFN)- $\gamma$ and tumor necrosis factor (TNF)- $\alpha$. It is also known that the exogenous expression of PHB-1 reduces basal autophagy as well as that induced by TNF- $\alpha^{21}$.

After the interaction between the viral particle and the host-cell receptor, the former is internalized in the cell through endocytosis. Inside the endosome, there is a reduction in $\mathrm{pH}$ due to the pumping of $\mathrm{H}^{+}$ions, which leads to a conformational reorganization of the E1-E2 heterodimer. In the glycoprotein E1, dominion II is exposed and fusion is carried out between the membrane of the endosome and that of the viral particle, thus releasing the nucleocapsid of the viral genome ${ }^{13}$. The interaction of the largest RNA subunit 605 with the proteins of the nucleocapsid signals its decoupling, thus releasing the genome. This is a highly conserved mechanism among Alphavirus ${ }^{14}$.

Once the viral genome (49S) is released in the host cell, the translation of the first ORF is carried out, this codifying for the synthesis of non-structural proteins (NSP1, NSP2, NSP3, NSP4) by means of the production of a polyprotein named P1234. The latter is processed proteolytically, generating the complex of viral replication (Fig. 2). NSP1 participates in the synthesis of the complementary chain of viral RNA as well as in the methylation and binding of CAP to the 5' extreme of the viral genome. NSP2 presents activity of RNA helicase, RNA triphosphate and proteinase, and inhibits the transcription of cellular mRNAs. NSP3 participates in the production of the negative chain of viral RNA. NSP4 is the polymerase RNA dependent on DNA ${ }^{2}$.

After the first ORF is translated, the complementary chain of viral RNA (negative chain) is produced. This serves as a template for the transcription of the second ORF known as subgenomic RNA 26S. The translation of this ORF gives rise to the generation of the structural proteins, $\mathrm{C}, \mathrm{E} 3, \mathrm{E} 2,6 \mathrm{k}$ and $\mathrm{E} 1$. The $\mathrm{C}$ and $6 \mathrm{k}$ proteins are accumulated in the cellular cytoplasm to form new nucleocapsids, which are assembled with a copy of the viral genome by means of proteolytic cuts.

Proteins E3, E2, and E1 undergo post-translation processing, being glycosylated in the endoplasmic reticulum. They are then sent to the Golgi apparatus to be later transported in vesicles to the cell membrane. When the nucleocapsid interacts with the accumulated glycoproteins in the cell membrane, the viral particles undergo a maturation process by acquiring the membrane envelope, and then finally are released by means of exocytosis ${ }^{17}$. It is important to mention that whereas the synthesis and translation of subgenomic 26CC RNS remains constant, the synthesis of the NSPs decreases and the transcription of genomic RNA 49S increases to the extent that the infection progresses inside the cell ${ }^{14,19}$.

Once a mosquito infected with CHIKV bites a healthy individual, the virus first multiplies in the fibroblasts located in the epithelium, and then, through infected macrophages, it disseminates to the lymph nodes. Additionally, the virus disseminates to the liver and joints through the blood flow that transports the virions produced ${ }^{17}$. The virus continues to propagate itself, evidenced by a viral load of up to $10^{8} \mathrm{PFU} / \mathrm{ml}$ (viremia phase) that has been detected at these sites $^{22}$. Later, it disseminates to the entire organism, thus initiating the signs and symptoms of the disease. The incubation period varies from 2-12 days ${ }^{18}$. The active infection only occurs in cells permissive to CHIKV. In mice, these cells primarily consist of muscle, joints, and skin fibroblasts. However, they have also been found in epithelial and endothelial cells of different organs, such as the liver, spleen, and brain ${ }^{17}$. 
Figure 2. General structure of chikungunya virus as well as genomic configuration and proteins expressed. The particles of this Alphavirus are 60-70 nm in diameter, are wrapped in an envelope, and contain a genome of approximately $11,805 \mathrm{nts}$. Initially, non-structural proteins are expressed and subgenomic RNA is generated. This gives rise in a second phase of transcription to structural viral proteins and the RNA template for copying the genomes of the viral progeny.
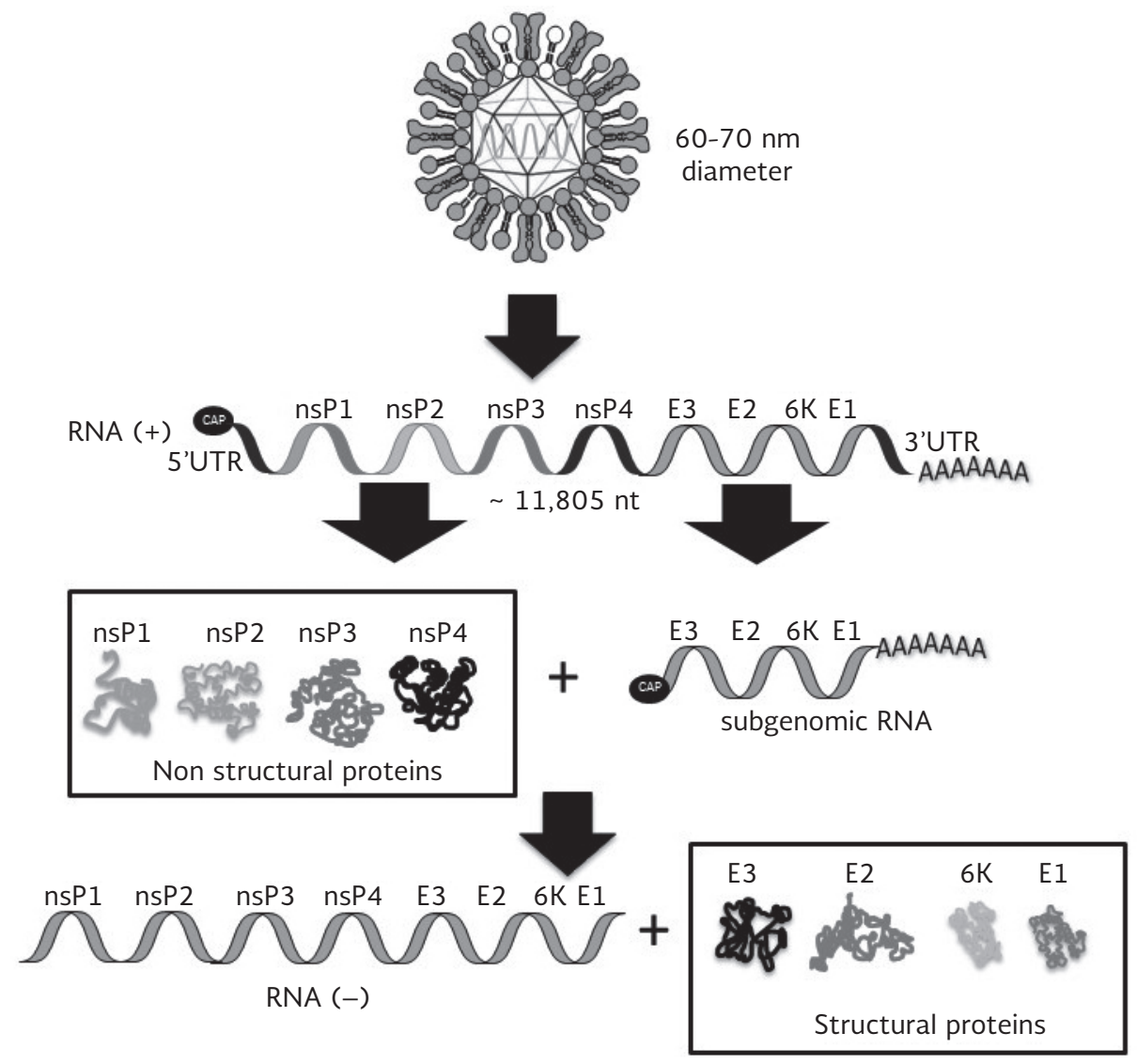

CHIKV induces a self-limiting disease, as it is eventually eliminated from the organism. The mechanisms of the innate immune response, mainly the production of IFN-I $\alpha / \beta^{17}$, and later those of adaptive immunity, the IgM and IgG antibodies, circumscribe the infection and finally control and eliminate it from the organism ${ }^{23,24}$.

\section{TRANSMISSION OF CHIKV}

CHIKV is transmitted to humans through a bite from a female Aedes mosquito, especially two species ${ }^{17}, A$. aegypti and $A$. albopictus. The former is considered the primary vector in the transmission of the disease since it is commonly associated with human habitat. However, during the outbreak of this virus on La Réunion Island in 2006, as well as in Africa and India, A. albopictus was also identified as an efficient vector, particularly from the ECSA genotype. This event was attributed to adaptive mutations in the genome of
CHIKV within the codifying genes for two SPs, E1 and $E 2^{16}$, mainly involving the mutation of A226V in the E1 protein. This change favors replication within the A. albopictus vector and the efficiency of the interaction of the virus with the host cell receptor ${ }^{15}$.

The virus circulates in nature through two cycles of transmission: the sylvatic (enzootic) cycle and the urban (epidemic) cycle, which are found in distinct geographic areas $^{24}$. In Africa, CHIKV is maintained through the sylvatic cycle, in which non-human primates are the primary reservoirs. This situation leads to frequent outbreaks in urban areas $^{15}$. Typically, these outbreaks coincide with the season of intense rain and the corresponding increase in mosquito population density. The species of mosquitoes that transmit CHIKV in Africa have been identified as $A$. furcifer, A. taylori, A. vittatus, A. fulgens, A. luteocephalus, A. dalzieli, A. vigilax, A. camptorhyntites and A. africanus. Culex annulirostris and Mansonia uniformis are also considered competent vectors ${ }^{25}$. 
As a consequence of population movements from endemic zones of Africa (e.g. Kenya and Comoro islands) to territory where the vector but not the virus previously existed, CHIKV has become an emerging virus. During the years 2005 and 2006, there were multiple outbreaks in India and the islands of the Indian Ocean, including La Réunion Island, in urban cycles of viral transmission ${ }^{1,2,4}$. In these cycles, humans in urban zones constitute the main host and the virus disperses successfully by means of human-mosquitohuman transmission. The species that participate in this transmission are A. aegypti and A. albopictus, as previously mentioned, leading to massive outbreaks ${ }^{24}$.

Once the mosquito bites an infected host, the virus arrives to the intestinal tract of the insect, multiplies in the vector's cells, and disseminates to the salivary glands. Then, the mosquito can transmit the virus in each feeding for the rest of its lifetime. To date, there has been no consistent evidence of transovarial transmission in the vectors ${ }^{26}$.

\section{CLINICAL PRESENTATIONS}

With a mosquito bite, viral particles are deposited in the skin, from where they eventually reach the lymph nodes and then the blood flow. They are then distributed to target organs that include joints, muscle, and skin (Fig. 3). With less frequency, the virus can affect the liver or cause encephalopathy, encephalitis, myocarditis, and heart blockage ${ }^{27}$. Although $5-15 \%$ of individuals suffer from asymptomatic infection ${ }^{26}$, the rest generally develop symptoms that progress from the acute to the chronic phase ${ }^{25}$.

\section{Acute phase}

The acute phase lasts 3-10 days and is characterized by the abrupt presentation of fever $\left(\geq 39^{\circ} \mathrm{C}\right)$. Other symptoms follow during the next few days ${ }^{26}$. Joint pain is reported in $87-98 \%$ of the cases. These two symptoms are the most characteristic of this disease.

Joint pain exists in more than one joint and is usually bilateral (symmetrical), occurring mainly in the peripheral joints (knees, ankles, hands, wrists) ${ }^{28}$. There is myalgia in $46-72 \%$ of the cases, affecting arms, thighs, and calves ${ }^{25}$. This clinical picture is called chikungunya fever (CHIKF) and tends to be limiting and even disabling in relation to the normal physical activity of individuals ${ }^{24,29}$.

The exanthema that appears in $40-50 \%$ of cases is of the petechial or maculopapular type, mainly affecting the limbs, trunk, and face, and can cause pruritus. The lesions are transitory and generally appear 2-5 days after disease onset ${ }^{29}$. Other symptoms that are less common are diarrhea, vomiting, edema on limbs, bleeding, otitis, and ocular disease (especially anterior uveitis) ${ }^{30-32}$. Some of the more severe manifestations, which are infrequently found, include neurological diseases such as meningoencephalitis, the Guillain-Barré syndrome, myocarditis, and multiorgan failure. The latter can be fatal, particularly in neonates and older adults with comorbidity ${ }^{33,34}$. Laboratory findings from persons in the acute stage of the disease have evidenced lymphopenia (500-1000 cells $/ \mathrm{mm}^{3}$ ) and moderate thrombocytopenia $\left(100,000-150,000\right.$ cells $\left./ \mathrm{mm}^{3}\right)$. Other uncommon abnormalities include leukopenia, elevation of hepatic enzyme levels, anemia, elevated creatinine level, and hypocalcemia ${ }^{18}$.

In neonates, CHIKF can be accompanied by convulsions, peripheral cyanosis, podalic edema, and epithelial vesicular lesions that eventually dry and scale ${ }^{35,36}$. This disease is usually considered benign in children ${ }^{37}$. However, neurological manifestations have been reported that include febrile convulsions, meningeal syndrome, acute encephalopathy, diplopia, aphasia, acute disseminated encephalomyelitis, and encephalitis ${ }^{35,38-40}$. The development of chronic arthralgia and exacerbation of underlying medical conditions is unusual ${ }^{26}$.

\section{Chronic phase}

After the diverse outbreaks and epidemics of chikungunya occurred in different regions of Africa, Asia and Europe, follow-up studies generated sufficient evidence to indicate that the infection with this virus can induce chronic rheumatic diseases. In adults, these conditions can last months or even years after the infection, while they are less common in children ${ }^{19,25,37}$.

The musculoskeletal disorders include arthralgia, inflammatory arthritis, polyarthralgia, tenosynovitis, enthesitis, and exacerbation of existing rheumatic disease ${ }^{29,41-46}$. Other less common symptoms include neuropathy, cerebral disorder, neurosensory deficiency, burning mouth syndrome, paresthesia, cubital 
Figure 3. Cells and target organs of chikungunya virus in humans. The virus is deposited on the skin during a mosquito bite, where it has been reported that cells like fibroblasts capture it. Later, the virus reaches the peripheral lymph nodes and arrives to the blood flow, causing viremia. The macrophages are often found infected by the virus and the main target organs are joints, skeletal muscle, liver and brain ${ }^{17}$.

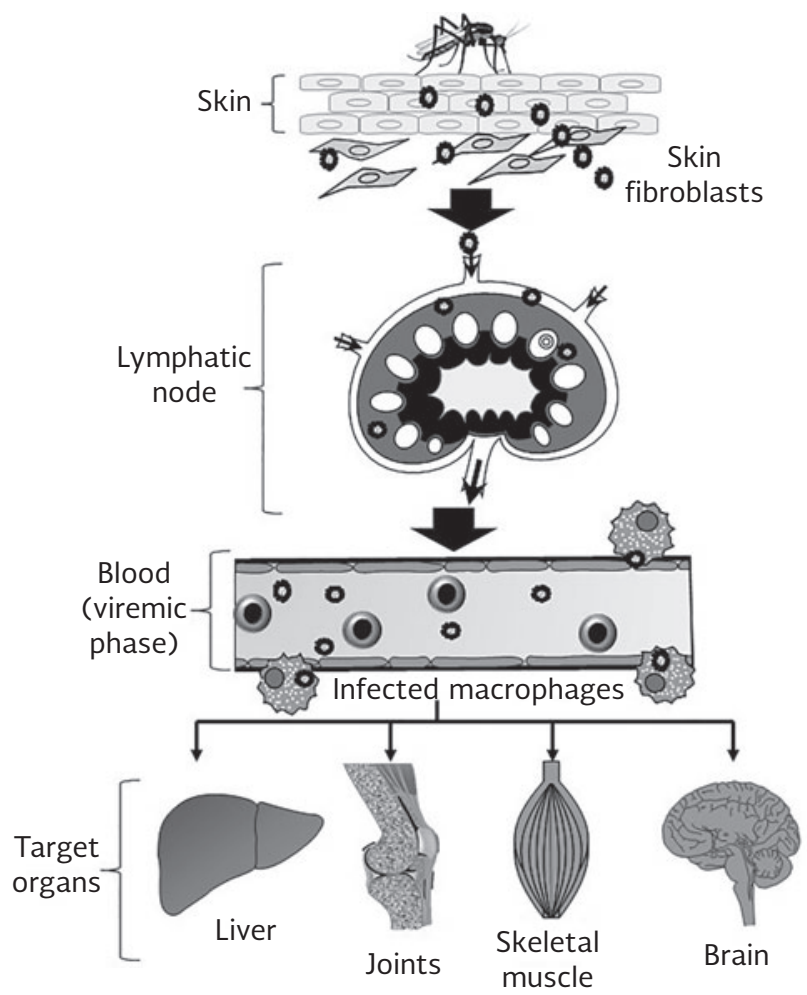

tunnel syndrome, gastrointestinal disorders, exanthema, pruritus, bursitis, and synovitis $28,36,44,47-49$.

Infection with CHIKV has been associated with destructive rheumatoid arthritis, which is similar to rheumatoid arthritis and induces a similar inflammatory response, although the laboratory tests are negative for the rheumatoid factor and the antibodies for cyclic citrullinated peptides (CCP) $26,44,50$. Radiographic studies of some of these individuals show bone erosion, swollen joints and synovitis ${ }^{44,51}$. The symptoms can be recurrent or chronic and can affect multiple joints (mainly those previously injured), which significantly diminishes the quality of life of the patient both physically (regarding function, pain and general health) and psychological ${ }^{18,52,53}$.

The development of arthralgia may be due to continuous inflammation in joints in response to viral antigens, evidenced by the fact that viral RNA has been detected in perivascular macrophages ${ }^{54}$. Risk factors for the development of chronic arthralgia identified to date include advanced age, long duration of the acute phase of $\mathrm{CHIKF}^{53}$ with more than six joints manifesting pain ${ }^{19}$, existing joint disease ${ }^{39}$, and a delayed adaptive immune response (mainly lgG neutralizing antibodies) ${ }^{55}$.

\section{Congenital infection}

Pregnant women with detectable viremia a few days before childbirth can transmit CHIKV to the newborn, which can result in a severe neonatal disease, generally encephalopathy followed by neurodisability ${ }^{3,56}$. Other signs and symptoms observed in newborns are convulsions, thrombocytopenia, hypotension, ventricular dysfunction, pericarditis, hyperechoic coronary arteries, parenchymal hemorrhage, and cytotoxic edema. It has been demonstrated that maternal-fetal transmission occurs due to contact of the product with infected maternal blood during childbirth ${ }^{57}$.

There is no specific antiviral drug treatment against $\mathrm{CHIKV}$. Nonetheless, symptomatic treatment includes acetaminophen to relieve the fever and nonsteroid anti-inflammatory drugs (e.g. paracetamol) for poly$\operatorname{arthralgia}^{18}$.

\section{PATHOGENESIS OF CHIKUNGUNYA VIRUS DISEASE}

Alphavirus, including CHIKV, cause severe forms of diseases such as chronic and highly disabling arthralgia/arthritis. Chronic symptomatology is observed with greater frequency in persons over 60 years of age that have very high viremia ( $>10^{10} \mathrm{PFU} / \mathrm{ml}$ ) during the acute phase of the disease ${ }^{27}$. The infection is initially very rapid and the virus is typically eliminated 5-7 days after onset of the fever. During the infection there is a robust and rapid activation of dendritic, NK/ CD4+ and CD8+ cells. Persistently high levels of IL-12 are mainly found in individuals with chronic symptoms, mostly in persons with rheumatoid arthritis, as inflammation provoked by CHIKV infection can cause bone erosion and severe arthralgia.

The activity of osteoclasts increases, thus promoting bone absorption ${ }^{58}$. Additionally, the activity of osteoblasts is inhibited during infection, which leads to the inhibition of bone formation ${ }^{59}$. The differentiation of osteoclasts from their precursors requires participation of the inductor cytokine RANKL (receptor activator for 
the nuclear factor $\mathrm{kB}$ ligand) ${ }^{60}$ and the interaction with its RANK receptor ${ }^{61}$. The activity of RANKL is inhibited by osteoprotegerin (OPG), a natural receptor that functions as a decoy for RANKL and blocks its interaction with RANK ${ }^{62}$ (Fig. 4). The concentrations of OPG and RANKL are maintained in a proportion that regulates the process of osteoclastogenesis ${ }^{63}$. When the concentration of RANKL rises, the production of osteoclasts increases, which leads to greater bone absorption.

Infections by Alphavirus share some common characteristics with other diseases such as rheumatoid arthritis $^{64}$. Replication of CHIKV inside cells in biopsies of synovial tissues has been clearly demonstrated. Pulklia, et al. showed the direct infection of primary synoviocytes with CHIKV. These infected cells attract monocytes/ macrophages and induce the formation of osteoclasts ${ }^{56}$. Primary cultures of osteoblasts have great susceptibility to infection with CHIKV, an infection that promotes the formation of osteoclasts and the loss of bone tissue ${ }^{65}$.

The innate immune system acts as the front line against an invasion by Alphavirus. There is increasing evidence of an immunopathogenesis due to the over-activation of the immune system by these viruses ${ }^{66}$. Apparently, the infiltration of macrophages to the joints determines the severity and persistence of the infection. The persistent infection of perivascular synovial macrophages by CHIKV and the constitutive infiltrate of CD14+ monocytes to the interior of the synovial cavity have been observed 18 months after the onset of symptoms in individuals infected with $\mathrm{CHIKV}^{54}$. During such an infection, a large number of cytokines, chemokines, and growth factors are stimulated in the plasma of these persons. Accordingly, a variety of interleukins have been detected: IL-1beta, IL-5, IL-6, IL-7, IL-10, IL-15 and IL-17. Ligands of chemokines found include CCL-3, CCL-4, CCL-2 (MCP-1) and CCL-5 (RANTES). Finally, granulocyte-macrophage colonystimulating factor (GM-CSF) has been found ${ }^{67,68}$.

In synovial liquid of infected individuals, there are important levels of CCL-2, IL-16 and IL- $8^{63}$, as well as elevated concentrations of RANKL, which could directly lead to bone loss ${ }^{69}$. These observations correlate with findings in animal models, such as mice and primates, in which it has been demonstrated that IL- 6 promotes the formation and liberation of RANKL. Hence, a probable strategy for controlling the infection is the use of anti-IL-6 antibodies ${ }^{70}$.
In the infection by Alphavirus, an increase has been found in the activation of T CD4+ lymphocytes ${ }^{54,71}$, which differentiate to Th17 and infiltrate the synovial space, possibly promoting local inflammation ${ }^{72}$.

\section{FINAL REMARKS}

It is important to consider that diverse diseases have a clinical presentation similar to that observed with a $\mathrm{CHIKV}$ infection. There are a great number of clinical conditions that must be ruled out to confirm the diagnosis and these include: leptospirosis, malaria, infections with other alphaviruses, and other viral entities that cause exanthema.

Even though CHIKF is characterized by fever with polyarthralgia, these indicators are unspecific. Moreover, the infection can take place in a subclinical form or coexist with other infections like dengue ${ }^{65}$. Therefore, diseases that should be considered in a differential diagnosis vary in relation to the relevant epidemiological characteristics, such as place of residence, travel to endemic zones, and exposure to mosquito bites ${ }^{6}$.

In the differential diagnosis of CHIKV in Mexico, it is of great importance to consider DENV, due to a high similarity between the clinical manifestations of these two infections, as well as the high incidence of the latter agent in this country. Symptoms like myalgia, arthralgia, and exanthema are more associated with CHIKV, while thrombocytopenia may be more indicative of dengue ${ }^{40,67}$. Despite the broad similarity between both diseases, CHIKF has a more acute onset and lasts a shorter time; additionally, maculopapular exanthema is more frequent and joint pain is more intense/localized and highly incapacitating.

In the absence of a vaccine or antiviral drug on the market, vector control is the only currently available strategy for controlling CHIKV. The previous experience with DENV control efforts is not encouraging. The virus spread throughout the Americas was imminent due to inefficient vector control and the emergence of resistance to insecticides in mosquitoes. Nevertheless, it is essential to continue efforts to improve epidemiological surveillance of CHIKV and other viruses by strengthening the health services and facilities at different levels, mainly for primary care, to detect new cases of the virus in a timely manner. Moreover, 
Figure 4. Infection with Alphavirus and its effect on osteoclastogenesis through RANKL. The osteoclasts differentiate from their precursors due to the effect of RANKL and the interaction with its receptor RANK. The binding of RANKL to RANK is inhibited by the decoy protein osteoprotegerin, which allows the maturing of osteoclasts. The changes that occur during Alphavirus infections induce an increase in RANKL that is not captured by osteoprotegerin, interfering with osteoclastogenesis ${ }^{65}$.

CCL: chemokine ligand; IL: interleukin; OPG: osteoprotegerin; RANKL: receptor activator for the nuclear factor kB ligand.



efforts to develop novel treatment strategies to fight this severe viral infection should continue.

\section{REFERENCES}

1. Kariuki M, Nderitu L, Ledermann JP, et al. Tracking epidemic chikungunya virus into the Indian Ocean from East Africa. J Gen Virol. 2008;89:2754-60.

2. Schuffenecker I, Iteman I, Michault A, et al. Genome microevolution of chikungunya viruses causing the Indian Ocean outbreak. PLoS Med. 2006;3:e263.

3. Gérardin P, Barau G, Michault A, et al. Multidisciplinary prospective study of mother-to-child chikungunya virus infections on the island of La Réunion. PLoS Med. 2008;5:e60.

4. Mavalankar D, Shastri P, Raman P. Chikungunya epidemic in India: a major public-health disaster. Lancet Infect Dis. 2007;7: 306-7.

5. Leparc-Goffart I, Nougairede A, Cassadou S, Prat C, Lamballiere X. Chikungunya in the Americas. Lancet. 2014;383:514.

6. Weaver SC. Arrival of Chikungunya virus in the New World: Prospects for spread and impact on public health. PLoS Negl Trop Dis. 2014;8:e2921.

7. Morens D, Fauci AS. Chikungunya at the door - déjà vu all over again? N Engl J Med. 2014;371:885-7.

8. Tsetsarkin KA, Vanlandingham DL, McGee CE, Higgs S. A single mutation in chikungunya virus affects vector specificity and epidemic potential. PLoS Pathog. 2007;2:e201.

9. Kautz TF, Díaz-González EE, Erasmus JH, et al. Chikungunya virus as cause of febrile illness outbreak, Chiapas, Mexico, 2014. Emerg Infect Dis. 2015;21:2070-3.

10. Díaz-González EE, Kautz TF, Dorantes-Delgado A, et al. First report of Aedes aegypti transmission of chikungunya virus in the Americas. Am J Trop Med Hyg. 2015;93:1325-9.
11. Díaz-Quiñonez JA, Escobar-Escamilla N, Ortíz-Alcántara J, et al. Identification of Asian genotype of chikungunya virus isolated in Mexico. Virus Genes. 2016:52:127-9.

12. Cigarroa-Toledo N, Blitvich BJ, Cetina-Trejo RC, et al. Chikungunya virus in febrile humans and Aedes aegypti mosquitoes, Yucatan, Mexico. Emerg Infect Dis. 2016;22:1804-7.

13. Fernández-Salas I, Díaz-González EE, López-Gatell H, Alpuche-Aranda CM. Chikungunya and zika virus dissemination in the Americas: different arbovirus reflecting the same spreading routes and poor vector-control policies. Curr Opin Infect Dis. 2016;29: 467-75.

14. Solignat M, Gay B, Higgs S, Briant L, Devaux C. Replication cycle of chikungunya: A re-emerging arbovirus. Virol J. 2009;393:183-97.

15. Tsetsarkin KA, Chen R, Sherman MB, Weaver SC. Chikungunya virus: evolution and genetic determinants of emergence. Curr Opin Virol. 2011;1:310-7.

16. Sumathy K, Ella KM. Genetic diversity of Chikungunya virus, India 2006-2010: Evolutionary dynamics and serotype analyses. J Med Virol. 2012;84:462-70.

17. Schwartz O, Albert ML. Biology and pathogenesis of chikungunya virus. Nat Rev Microbiol. 2010;8:491-500.

18. Staples JE, Powers A, Tomashek K, et al. Preparación y respuesta ante la eventual introducción del virus chikungunya en las Américas. Washington, D.C. CDC/OPS (2011). ISBN: 978-9275-31632-0.

19. Thiberville SD, Boisson V, Gaudart J, Simon F, Flahault A, Lamballerie X. Chikungunya fever: A clinical and virological investigation of outpatients on Reunion Island, South-West Indian Ocean. PLoS Negl Trop Dis. 2013;7:e2004.

20. Wintachai P, Wikan N, Kuadkitkan A, et al. Identification of prohibitin as a Chikungunya virus receptor protein. J Med Virol. 2012;84:1757-70.

21. Kathiria AS, Burcher LD, Feagins LA, Souza RF, Boland R, Theiss AL. Phohibitin 1 modulates mitochondrial stress-related autophagy in human colonic epithelial cells. PLoS One. 2012;7:e31231.

22. Powers AM, Logue $\mathrm{CH}$. Changing patterns of chikungunya virus: Re-emergence of a zoonotic arbovirus. J Gen Virol. 2007;88: 2363-77. 
23. Lum FM, Teo TH, Lee WW, Kam YM, Rénia L, Ng LF. An essential role of antibodies in the control of chikungunya virus infection. J Immunol. 2013;190:6295-302.

24. Simon F, Javelle E, Oliver M, Leparc-Goffart I, Marimoutou C. Chikungunya virus infection. Curr Infect Dis Rep. 2011;13:218-28.

25. Thiberville S, Moyen N, Dupuis-Maguiraga L, et al. Chikungunya fever: Epidemiology, clinical syndrome, pathogenesis and therapy. Antiviral Res. 2013;99:345-70.

26. Gasque P, Couderc T, Lecuit M, Roques P, Ng LF. Chikungunya virus pathogenesis and immunity. Vector Borne Zoonotic Dis. 2015;15:241-9.

27. Van Dujil-Richter MK, Horrnweg TE, Rodenhuis-Zybert IA, Smit JM. Early events in chikungunya virus infection-from virus cell binding to membrane fusion. Viruses. 2015;7:3647-74.

28. Gérardin P, Fianu A, Michault A, et al. Predictors of chikungunya rheumatism: A prognostic survey ancillary to the TELECHIK COhort study. Arthritis Res Ther. 2013;15:R9.

29. Burt FJ, Ralph MS, Rulli NE, Mahalingam S, Heise MT. Chikungunya: a re-emerging virus. Lancet 2012;379:662-71.

30. Borgherini G, Poubeau P, Staikowsky F, et al. Outbreak of chikungunya on Réunion Island: Early clinical and laboratory features in 157 adult patients. Clin Infect Dis. 2007;44:1401-7.

31. Lakshmi V, Meeraja M, Sunnalaxmi MV, et al. Clinical features and molecular diagnosis of chikungunya fever from South India. Clin Infect Dis. 2008;46:1436-42.

32. Mahendradas P, Avadhani K, Shetty R. Chikungunya and the eye: A review. J Ophthalmic Inflamm Infect. 2013;3:35.

33. Lemant J, Boisson V, Winer A, et al. Serious acute chikungunya virus infection requiring intensive care during the Réunion Island outbreak in 2005-2006. Crit Care Med. 2008;36:2536-41.

34. Economopoulou A, Dominguez M, Helynck B, et al. Atypical chikungunya virus infections: Clinical manifestations, mortality and risk factors for severe disease during the 2005-2006 outbreak on Réunion. Epidemiol Infect. 2009;137:534-41.

35. Valamparampil J], Chirakkarot S, Letha S, Jayakumar C, Gopinathan KM. Clinical profile of Chikungunya in infants. Indian J Pediatr. 2009;76:151-5.

36. Nkoghe D, Kassa RF, Caron M, et al. Clinical forms of chikungunya in Gabon, 2010. PLoS Negl Trop Dis. 2012;6:e1517.

37. Sebastian MR, Lodha R, Kabra SK. Chikungunya infection in children. Indian J Pediatr. 2009;76:185-9.

38. Le Bomin A, Hebert JC, Marty P, Delaunay P. [Confirmed chikungunya in children in Mayotte. Description of 50 patients hospitalized from February to June 2006]. Med Trop (Mars). 2008;68: 491-5.

39. Robin S, Ramful D, Le Seach F, Jaffar-Bandjee MC, Rigou G, Alessandri JL. Neurologic manifestations of pediatric chikungunya infection. J Child Neurol. 2008;23:1028-35.

40. Lewthwaite P, Vasanthapuram R, Osborne JC, et al. Chikungunya virus and central nervous system infections in children, India. Emerg Infect Dis. 2009;15:329-31.

41. Simon F, Javelle E, Oliver M, Leparc-Goffart I, Marioutou C. Chikungunya infection: An emerging rheumatism among travelers returned from Indian Ocean islands. Report of 47 cases. Medicine (Baltimore). 2007;86:123-37.

42. Borgherini G, Poubeau P, Staikowsky F, et al. Persistent arthralgia associated with chikungunya virus: A study of 88 adult patients on Reunion island. Clin Infect Dis. 2008;47:469-75

43. Sissoko D, Malvy D, Ezzedine K, et al. Post-epidemic chikungunya disease on Reunion Island: Course of rheumatic manifestations and associated factors over a 15-month period. PLoS Negl Trop Dis. 2009;3:e389

44. Manimunda SP, Vijayachari P, Uppoor R, et al. Clinical progression of chikungunya fever during acute and chronic arthritic stages and the changes in joint morphology as revealed by imaging. Tran R Soc Trop Med Hyg. 2010;104:392-9.

45. Schilte C, Staikovsky F, Couderc T, et al. Chikungunya virusassociated long-term arthralgia: A 36-month prospective longitudinal study. PLoS Negl Trop Dis. 2013;7:e2137.

46. Waymouth HE, Zoutman DE, Towheed TE. Chikungunya-related arthritis: Case report and review of the literature. Semin Arthritis Rheum. 2013;43:273-8.

47. Chopra A, Anuradha V, Ghorpade R, Saluja M. Acute chikungunya and persistent musculoskeletal pain following the 2006 Indian epidemic: A 2-year prospective rural community study. Epidemiol Infect. 2012;140:842-50

48. Moro ML, Grilli E, Corvetta A, et al. Long-term chikungunya infection clinical manifestations after an outbreak in Italy: A prognostic cohort study. J Infect. 2012;65:165-72

49. Mohd-Zim MA, Sam IC, Syed-Omar SF, Chan YF, AbuBakar S Kamarulzaman A. Chikungunya infection in Malaysia: Compari- son with dengue infection in adults and predictors of persistent arthralgia. J Clin Virol. 2013;56:141-5.

50. Malvy D, Ezzedine K, Mamani-Matsuda M, et al. Destructive arthritis in a patient with chikungunya virus infection with persistent specific IgM antibodies. BMC Infect Dis. 2009;9:200

51. Bouquillard E, Combe B. A report of 21 cases of rheumatoid arthritis following chikungunya fever. A mean follow-up of two years. Joint Bone Spine. 2009;76:654-7.

52. Marimoutou C, Vivier E, Oliver M, Boutin JP, Simon F. Morbidity and impaired quality of life 30 months after chikungunya infection: Comparative cohort of infected and uninfected French military policemen in Réunion Island. Medicine (Baltimore). 2012;91: 212-19.

53. Couturier E, Guillemin F, Mura M, et al. Impaired quality of life after chikungunya virus infection: A 2-year follow-up study. Rheumatology (Oxford). 2012;51:1315-22.

54. Hoarau JJ, Jaffar-Bandjee MC, Krejbich-Trotot $P$, et al. Persistent chronic inflammation and infection by chikungunya arthritogenic alphavirus in spite of a robust host immune response. J Immunol. 2010;184:5914-27.

55. Kam Y, Simarmata D, Chow A et al. Early appearance of neutralizing immunoglobulin G3 antibodies is associated with chikungunya virus clearance and long-term clinical protection. J Infect Dis. 2012;205:1147-54

56. Shenoy S, Pradeep GC. Neurodevelopmental outcome of neonates with vertically transmitted chikungunya fever with encephalopathy. Indian Pediatr. 2012;49:238-40.

57. Ramful D, Sampériz S, Fritel $X$ et al Antibody kinetics in infants exposed to chikungunya virus infection during pregnancy reveals absence of congenital infection. J Infect Dis. 2014;209:1726-30.

58. Gravallese EM, Harada Y, Wang JT, Gorn AH, Thornhill TS, Goldring SR. Identification of cell types responsible for bone resorption in rheumatoid arthritis and juvenile rheumatoid arthritis. Am J Pathol. 1998;52:943-51.

59. Walsh NC, Reinwald S, Manning CA, et al. Osteoblast function is compromised at sites of focal bone erosion in inflammatory arthritis. J Bone Miner Res. 2009;24:1572-85.

60. Kong $Y Y$, Yoshida $H$, Sarosi I, et al. OPGL is a key regulator of osteoclastogenesis, lymphocyte development and lymph node organogenesis. Nature. 1999;397:315-23.

61. Dougall WC, Glaccum M, Charrier K, et al. RANK is essential for osteoclast and lymph node development. Genes Dev. 1999;13: 2412-24.

62. Simonet WS, Lacey DL, Dunstan CR, et al. Osteoprotegerin: a novel secreted protein involved in the regulation of bone density. Cell. 1997;89:309-19.

63. Horwood NJ, Elliot J, Martin TJ, Gillespie MT. Osteotropic agents regulate the expression of osteoclast differentiation factor and osteoprotegerin in osteoblastic stromal cells. Endocrinology. 1998;139:4743-6.

64. Chopra A, Anuradha V, Lagoo-Joshin V, Kunjir V, Salvi S, Saluja M. Chikungunya virus aches and pains: an emerging challenge. Arthritis Rheum. 2008:58:2921-2.

65. Phuklia W, Kasisith J, Modhiran N, et al. Osteoclastogenesis induced by CHIKV- infected fibroblast-like synoviocytes: a possible interplay between synoviocytes and monocytes/macrophages in CHIKV-induced arthralgia/arthritis. Virus Res. 2013; 177:179-88.

66. Chen W, Foo S-S, Sims NA, Herrero LJ, Walsh NC, Mahalingam S. Arthritogenic alphavirus: new insights into arthritis and bone pathology. Micro. 2015;234:35-43.

67. Chow A, Zhishenng H, Ong EK, et al. Persistent arthralgia induced by chikungunya virus infection is associated with interleukin- 6 and granulocyte macrophage colony stimulating factor. J Infect Dis. 2011;203:149-57.

68. Ng LF, Chow A, Sun Y-J, et al. IL-1beta, IL-6, and RANTES as biomarkers of chikungunya severity. PLoS One. 2009;4:e4261.

69. Noret M, Herrero L, Rulli N, et al. Interleukin 6, RANKL, and osteoprotegerin expression by chikungunya virus-infected human osteoblasts. J Infect Dis. 2012;206:455-7.

70. Lindbury BA, Rulli NE, Suhrbier A, et al. Macrophage-derived proinflammatory factors contribute to the development of arthritis and myositis after infection with an arthrogenic alphavirus. J Infect Dis. 2008;197:1585-93.

71. Wauquier N, Becquart P, Nkoghe D, Padilla C, Ndjoyi-Mbiquino $A$, Leroy EM. The acute phase of chikungunya virus infection in humans is associated with strong innate immunity and T CD8 cell activation. J Infect Dis. 2011;204:115-23.

72. Teo $\mathrm{TH}$, Lum FM, Claser C, et al. A pathogenic role for CD4+ T cells during chikungunya virus infection in mice. J Immunol. 2013;190:259-69. 